\title{
Smart Glasses for Caring Situations in Complex Care Environments: Scoping Review
}

Charlotte Romare ${ }^{1,2}$, CCRN, MSc; Lisa Skär ${ }^{2}, \mathrm{RN}, \mathrm{PhD}$

${ }^{1}$ Region Blekinge, Karlskrona, Sweden

${ }^{2}$ Department of Health, Blekinge Institute of Technology, Karlskrona, Sweden

\section{Corresponding Author:}

Charlotte Romare, CCRN, MSc

Region Blekinge

Intensive Care Unit

Karlskrona, 37185

Sweden

Phone: 46455731000

Email: charlotte.romare@ regionblekinge.se

\section{Abstract}

Background: Anesthesia departments and intensive care units represent two advanced, high-tech, and complex care environments. Health care in those environments involves different types of technology to provide safe, high-quality care. Smart glasses have previously been used in different health care settings and have been suggested to assist health care professionals in numerous areas. However, smart glasses in the complex contexts of anesthesia care and intensive care are new and innovative. An overview of existing research related to these contexts is needed before implementing smart glasses into complex care environments.

Objective: The aim of this study was to highlight potential benefits and limitations with health care professionals' use of smart glasses in situations occurring in complex care environments.

Methods: A scoping review with six steps was conducted to fulfill the objective. Database searches were conducted in PubMed and Scopus; original articles about health care professionals' use of smart glasses in complex care environments and/or situations occurring in those environments were included. The searches yielded a total of 20 articles that were included in the review.

Results: Three categories were created during the qualitative content analysis: (1) smart glasses as a versatile tool that offers opportunities and challenges, (2) smart glasses entail positive and negative impacts on health care professionals, and (3) smart glasses' quality of use provides facilities and leaves room for improvement. Smart glasses were found to be both a helpful tool and a hindrance in caring situations that might occur in complex care environments. This review provides an increased understanding about different situations where smart glasses might be used by health care professionals in clinical practice in anesthesia care and intensive care; however, research about smart glasses in clinical complex care environments is limited.

Conclusions: Thoughtful implementation and improved hardware are needed to meet health care professionals' needs. New technology brings challenges; more research is required to elucidate how smart glasses affect patient safety, health care professionals, and quality of care in complex care environments.

(JMIR Mhealth Uhealth 2020;8(4):e16055) doi: $\underline{10.2196 / 16055}$

\section{KEYWORDS}

anesthesia department; critical care; intensive care units; scoping review; smart glasses

\section{Introduction}

\section{Complex Care Environments}

Improvements in medical skills and technology have made health care increasingly complex [1]. Anesthesia departments and intensive care units (ICUs) represent two advanced, high-tech, and complex care environments [2,3]. In the anesthesia department, patients undergo planned or acute surgeries, treatments, or examinations. The patients are often under sedation or anesthesia, which affects vital organ functions. Specialized health care professionals are responsible for maintaining the patient's ventilation and handling changes in the homeostatic balance caused by sedation or anesthesia. Advanced technology, such as ventilators, physiological monitoring, and the anesthesia station, make this possible [2]. The most critically ill patients are admitted to the ICU. These 
patients can have failure in one or more vital organ systems, such as the cardiovascular, respiratory, or renal system. Numerous examinations and treatments are performed and used, such as mechanical ventilation, bronchoscopy, dialysis, and multiple potent drugs [3]. In both ICUs and anesthesia departments, changes in the patient's condition can occur rapidly and may demand an immediate response from health care professionals to save the patient's life, hence, close surveillance is vital. Health care in these complex care environments is based on well-trained and dedicated health care professionals, teamwork, and the use of technology to provide high-quality care and ensure patient safety $[2,3]$. Caring situations in complex care environments include, for example, advanced medical, technological, and caring components and the surrounding specific environment. In this study, we use the expression complex care environment to describe all these aspects in the contexts above.

\section{Patient Safety}

Patients being cared for in complex care environments are in a vulnerable state, due to their conditions and the treatments they need. According to the World Health Organization, patient safety work aims to prevent avoidable patient harm and provide a safe health care environment. They also state that delivering safe complex care is a challenge [4]. The use of advanced technology, such as ventilators and physiological monitoring, is a prerequisite for care in anesthesia departments and ICUs. Technology is known to increase patient safety and to enhance patient care [5], but technology also imposes risks. In 2019, the Emergency Care Research Institute (ECRI) included both ventilators and physiological monitoring on their annual top-10 list of health technology hazards [6]. This imposes continuous work for patient safety in complex care environments. Patient safety work is not only related to the use of technology. In complex situations, several factors interact; patient safety work is also related to other aspects, for example, working conditions and routines $[4,7]$. Health care professionals in complex care environments incorporate several factors into their surveillance during patient care in order to provide safe care [8]. Through close surveillance, health care professionals can support both the physical and emotional needs of the patient, to protect the patent from suffering and harm. This promotes a patient-safe way of working [9], as do proper implementation and use of new technology [7]. It is also important for new technology to add value to patient care and to bring desired consequences [10].

\section{Smart Glasses}

Smart glasses are a product suggested to aid health care professionals in numerous areas, such as surgery, accessing electronic health records, remote instructions, and education [11-13]. They are a computing device worn as a pair of glasses, which presents information within the user's field of view through a prism. Smart glasses are a platform for apps and can display text and images, use a camera, and communicate via Bluetooth and Wi-Fi. The user interacts with the smart glasses through physical input or voice commands [14]. Smart glasses can send and receive information online, or through local area networks, and the information can be displayed in the prism.
Smart glasses can also be used to communicate by voice or video and to capture pictures or video. The uses for smart glasses depend on the apps in the device; tailored apps provide the possibility for multiple purposes. The most well-known brand of smart glasses today is Google Glass, which was introduced to the market in 2013.

\section{Smart Glasses in Complex Care Environments}

According to our literature search, a few reviews have been published about smart glasses in surgical and nonsurgical settings. Different areas of use are described, such as to provide visualization during laparoscopy, to broadcast live surgery to medical students, to take pictures and record videos to facilitate medical documentation, to record encounters with patients, and to use as a navigational tool to maintain attention to the operative field [11-13,15-19]. The idea of head-mounted and hands-free equipment as an aid in anesthesia departments is not new [20]; health care professionals have shown interest in, and have seen the potential for, smart glasses in intensive care [21]. Since there is a growing interest in smart glasses and since technology might have an effect on patient safety, it is important to conduct a scoping review on smart glasses used by health care professionals in complex care environments in order to identify the knowledge and experiences in this field. In our study we use the term health care professionals to describe physicians with different levels of experience and training, registered nurses, specialized nurses, and other professionals working closely with patients, such as assistants. To our knowledge, only a few studies have been performed within our area of interest $[22,23]$. This indicates that the use of smart glasses in complex care environments is a new and evolving area, making it even more important to investigate. This field is novel, innovative, and has been found to have potential to improve both patient care and patient safety in other health care settings $[16,19]$. The aim of this study was, therefore, to highlight potential benefits and limitations with health care professionals' use of smart glasses in situations occurring in complex care environments.

\section{Methods}

\section{Design}

A scoping review was chosen as the methodology of this study since it addresses broad research questions and is advocated for new areas [24-26]. This review followed all six stages suggested by Arksey and O'Malley [25] and the methodological development by Levac et al [27]. Results are reported according to the PRISMA (Preferred Reporting Items for Systematic Reviews and Meta-Analyses) extension for scoping reviews (PRISMA-ScR) in order to increase methodological transparency [26].

\section{Data Search and Selection}

Step 1 was to identify the research question; a scoping review approach has been suggested [25,27] and our path toward the final aim was described in the Introduction. Step 2 was to identify relevant articles. Before we began the database searches, we consulted experienced librarians who assisted in choosing the most appropriate databases and search terms as suggested by Arksey and O'Malley [25]. PubMed and Scopus were chosen 
to cover research within both health care and engineering. Search terms were also discussed among the authors and with other researchers within the fields of nursing, medicine, and engineering. New search terms were added several times during the process. The final search terms are presented in Multimedia Appendix 1. As stated initially, only two articles were identified during our initial searches $[22,23]$, which made us broaden our searches to include vital signs monitoring, alarm management, and patient safety, since these are important aspects of care in complex care environments. This resulted in one additional article from a clinical setting [28] and two from simulated settings [29,30]. We also found articles about isolated events occurring in complex care environments, such as electrocardiogram (ECG) reading and cardiopulmonary resuscitation (CPR). We did not actively search for specific isolated events using those words as search terms in the database searches, but we did include articles found during our searches.
The database searches are presented in Multimedia Appendix 2.

Additional articles were identified using reference lists and research networks (ie, ResearchGate and Academia). The deadline for searching databases was set to April 2018, and the deadline for searching other sources was set to December 2018. Step 3 was the study selection of the scoping process [25,27]. The inclusion and exclusion criteria are presented in Textbox 1. We made no limitations on the publication date, since smart glasses are a new product.

Titles in the search results list were screened first, followed by the abstracts, if needed, in order to identify relevant articles. The full-text articles were obtained and read if they seemed eligible for this review. Screening was performed by the first author (CR) and discussed among the authors. A flowchart of the search process, similar to a PRISMA 2009 flow diagram [31], is presented in Figure 1.

Textbox 1. Inclusion and exclusion criteria for publications.

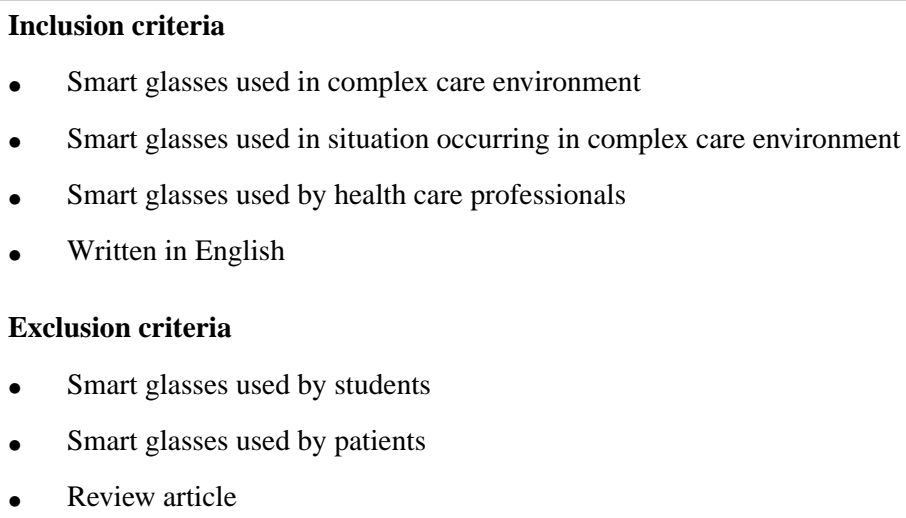

Figure 1. Flowchart of search.

\begin{tabular}{|c|c|}
\hline $\begin{array}{l}\text { Database search } \\
\text { Total }(n=1640) \\
\text { PubMed }(n=972) \\
\text { Scopus }(n=668)\end{array}$ & \\
\hline$\checkmark$ & $\begin{array}{l}\text { Articles excluded for not } \\
\text { meeting the aim or being a } \\
\text { duplicate } \\
(\mathrm{n}=1586)\end{array}$ \\
\hline $\begin{array}{l}\text { Articles assessed in full text } \\
\text { for eligibility } \\
(\mathrm{n}=54)\end{array}$ & \multirow{2}{*}{$\begin{array}{l}\text { Additional articles found } \\
\text { through other sources } \\
\text { (excluding duplicates) } \\
(\mathrm{n}=19)\end{array}$} \\
\hline$\sqrt{1}$ & \\
\hline $\begin{array}{l}\text { Total number of full-text } \\
\text { articles retrieved } \\
(n=73)\end{array}$ & \multirow{3}{*}{$\begin{array}{l}\text { Articles excluded: } \\
\text { No study conducted }(n=12) \\
\text { Not about smart glasses }(n=13) \\
\text { Not used by health care } \\
\text { professionals }(n=4) \\
\text { Not ICU/anesthesia } \\
\text { situation }(n=9) \\
\text { Focus on technological } \\
\text { specifications }(n=4) \\
\text { Not in English }(n=1) \\
\text { Reviews }(n=10)\end{array}$} \\
\hline$\checkmark$ & \\
\hline $\begin{array}{l}\text { Articles included in the } \\
\text { final scoping review } \\
(\mathrm{n}=20)\end{array}$ & \\
\hline
\end{tabular}




\section{Data Summary and Analysis}

Step 4 involved charting the data to gain an overview. This charting is presented in Multimedia Appendix 3. During step 5 , the results were collated, summarized, and reported [25]. This can be a challenging process and it is recommended to divide step 5 into three parts: analysis, reporting results, and considering the overall implications of the results. A qualitative content analysis is recommended [27], hence, we chose to follow Polit and Beck's [24] description of this process. Meaning units meeting the aim of this study were marked in the included articles and condensed while still retaining the core content. Notes about context were added to the condensed units. The condensed units were then continuously numbered, labelled with a code, sorted into subcategories, and then sorted into categories; hence, analysis was on a manifest level [24]. Neither the analysis nor the scoping process occurred in a one-way direction but went back and forth between the steps as more knowledge was obtained. Step 6-the last step-in the scoping process was to enable practitioners and consumers to contribute to the work. The results of this scoping review have been presented to, and discussed with, engineers, a physician, registered nurses, and nurses specialized in intensive care and anesthesiology.

\section{Results}

\section{Overview}

The aim of this study was to highlight potential benefits and limitations of health care professionals' use of smart glasses in situations occurring in complex care environments. A total of 20 articles [22,23,28-30,32-46] were found eligible for our scoping review and were included in the content analysis (see Multimedia Appendix 3). These included research articles $(16 / 20,80 \%)$, conference articles $(2 / 20,10 \%)$, a case report $(1 / 20,5 \%)$, and a correspondence $(1 / 20,5 \%)$. The included articles originated from the United States $(12 / 20,60 \%)$, European countries $(7 / 20,35 \%)$, and Australia (1/20, 5\%) and were published in a variety of scientific journals and conference proceedings. One article was published in 2012; the rest were published between 2014 and 2018. A majority of the articles were from simulated or laboratory settings $(11 / 20,55 \%)$ and 1 article out of $20(5 \%)$ was conducted in both a simulated and clinical setting; both qualitative and quantitative designs were used. During analysis, three categories were created: (1) Smart glasses as a versatile tool that offers opportunities and challenges, (2) Smart glasses entail positive and negative impacts on health care professionals, and (3) Smart glasses' quality of use provides facilities and leaves room for improvement.

\section{Smart Glasses as a Versatile Tool That Offers Opportunities and Challenges}

Smart glasses were found to be used in several situations occurring in complex care environments, including in daily practice [22,32], for vital signs monitoring [28-30], for consultation and assessment $[33,34]$, for CPR evaluation [35,36], for documentation (ie, verbal, photo, and video) [37-40], and for viewing medical images [41-46].
Smart glasses were found to be easy to use in procedural settings [30]. Procedures were performed correctly $[45,46]$ and with equivalent technique, both with and without smart glasses $[29,35]$. Increased time for completing tasks was noted when using smart glasses $[37,46]$. When using smart glasses for vital signs monitoring, abnormal signs were noted earlier than with traditional monitoring [29,30]; smart glasses were found suitable for this purpose $[28,30]$ and increased awareness of vital signs $[29,30]$. Even though smart glasses made it easier to monitor vital signs, especially if working alone, health care professionals did not feel that smart glasses could replace the traditional monitor [30]. Presenting vital signs in smart glasses made uninterrupted monitoring possible, even when engaged in other activities [23,32] or at a remote location [23].

Smart glasses provided the possibility to share information with colleagues $[22,32,37,40]$. In some cases, visual media from smart glasses caused the remote consultants to change the management plan for patients. The remote consultants mostly gained confidence in the management plans and found the visual media helpful [33]. Assessing patients remotely through smart glasses showed high agreement with on-site investigators, with assessment of pupil size as the least correlating parameter [34]. Gaining expert help through smart glasses' audio-video link during CPR was found to be helpful and reassuring. Technique and management improved, but CPR was sometimes interrupted, both because of the instructions given and by discussions with the remote expert [35]. Research found that smart glasses were eligible for educational purposes as well as for accessing patient medical records [32] and databases [22]. Furthermore, smart glasses were used to read patient barcodes for patient identification in order to increase patient safety [38]. The possibility of increasing patient safety through smart glasses was also mentioned by others [30,32].

Smart glasses could facilitate documentation, although text from voice recognition in a medical context needed improvement $[22,38]$; poor audio quality was seen as a contributing factor. Text was usually recognized when health care professionals talked clearly and slowly [22]. A context-specific vocabulary was suggested and the ability to review and edit the text was seen as necessary [38]. The default setting for both audio [38] and video recordings needed to be longer in order to be useful in clinical practice [22,38]. Smart glasses were found to be easy to use for video recordings [36] and provided good quality $[22,39]$. Video from smart glasses was rated better than video from a standard video camera. Both visibility and audibility were equivalent to that of an on-site observer. Health care professionals stated that they would be uncomfortable recording an actual event [36], and some were worried that they would be filmed unknowingly [22]. There was some discrepancy between what the user saw and what was recorded. In order to capture the right area of interest, the user had to angle the head $[22,35]$ to an uncomfortable position [22]. Difficulties in capturing the correct area of interest were also noted when taking photos with smart glasses; this and a decrease in sharpness were the main differences between smart glasses and an ordinary digital camera [37]. Others found no difference between photographing with smart glasses and an ordinary digital camera, but they preferred to preview photos on a larger 
screen than in smart glasses [38]. Some aspects of complex care were seen to be best documented by a photo [39] that could easily be captured by smart glasses, hands-free and without assistance [37-39]. Since smart glasses lack the ability to zoom, health care professionals sometimes had to come closer to the photo object than they preferred $[22,37]$.

The small size of the smart glasses' display caused dissatisfaction when working with medical images, as did the lack of zoom [41]. Health care professionals found it difficult to notice subtle findings in medical images [22]. To improve the concept, high-quality images were requested [41] and the provided ability to zoom and pan was appreciated by users [44]. Health care professionals were not confident in their interpretations of medical images in smart glasses [41], and interpretations were less correct when performed in smart glasses than when performed traditionally [41,43,44]. When interpreting streamed ECG in smart glasses, no difference was noted from standard conditions regarding noticing different rhythms [42].

\section{Smart Glasses Entail Positive and Negative Impacts on Health Care Professionals}

Smart glasses were described as new tools for health care professionals in the included articles. Health care professionals felt unfamiliar with smart glasses $[23,36]$ and noted that there was a learning curve $[30,44,45]$. If the smart glasses' camera was used improperly, the quality of images was affected [38]; practice [22] or training courses [40] were suggested. Health care professionals' general impressions of smart glasses were positive $[22,23,30,40]$ and they stated that they would like to use smart glasses again $[23,29,46]$. Health care professionals did not feel interrupted or disturbed by smart glasses during procedures or patient management [22,23,30,33,37,39]. No objective or subjective nervousness or anxiety were found [29], although some health care professionals did feel distracted by the smart glasses $[29,35,36]$, which affected their performance negatively [29,35]. Increased focus on, and quality of, the task performed using smart glasses were noted as a positive aspect; however, on the negative side, it was difficult to talk to the patient and to the smart glasses at the same time [40]. When using smart glasses during procedures, health care professionals gained increased focus on the procedural field, and ergonomics improved since they did not have to turn their heads to view monitors $[30,45,46]$. Health care professionals did, however, spend more time looking at the smart glasses display than they did at a traditional ultrasound screen [46]. Smart glasses were found to be comfortable to wear $[23,29,34,35,37,46]$. Some users who wore prescription glasses found it difficult to combine these with smart glasses [23,29,35], while others did not have this issue [36]. On smart glasses where the prism was fixed to the right eye, left-handed users reported discomfort [29]. Health care professionals reported eye strain and fatigue after using smart glasses $[23,36,42]$. Some health care professionals did not find it problematic to use smart glasses the whole day, while others found it infeasible [40].

\section{Smart Glasses' Quality of Use Provides Facilities and Leaves Room for Improvement}

This category involves aspects of technical performance, navigation, and hardware. The quality of photos and videos captured by smart glasses was positively evaluated [22,33,35,37,38,43-45], although photos from an ordinary digital camera received higher ratings [37]. With adequate lighting, no photos were over- or underexposed [38]. Smart glasses had no flash, which led to decreased photo quality in low-light environments, and overexposure occurred with overhead operating lamps [22]. Furthermore, the absence of the ability to zoom affected the possibility of getting the correct area in focus for the photos [22,37]. The smart glasses display was easily seen $[22,23]$ and the contrast improved if the background was dark. During videoconferencing, small letters were not legible [22] and the display was considered too small to provide all details on medical images, such as radiographs [43]. When communicating with others using smart glasses, the room needed to be quiet for good audibility [22].

Wi-Fi and/or Bluetooth were used for data transmission. Smart glasses were able to connect to Wi-Fi and Bluetooth without problems [22], but issues with Wi-Fi coverage were noted $[23,34,38]$. During data transmission, stuttering, cutoffs, and delays occurred $[22,23,34,46]$. Data saved in smart glasses were automatically uploaded to a cloud server when smart glasses were charged and connected to Wi-Fi. This could be avoided by connecting smart glasses to a computer prior to charging in order to transfer and delete data without uploading it to the server [22].

Smart glasses could be controlled by voice or physical input, such as using a touch pad, eyeblinks, or head movements. Controlling smart glasses through a temple touch pad was found to be easy and intuitive. In sterile environments [22] and when hands were busy or contaminated [38], hands-free handling was found useful. Voice control worked well in both silent and busy environments [37], but problems with voice control for video recordings were reported $[33,38]$. Features for controlling smart glasses by gestures were tested and appreciated by users $[22,37,38]$ but did not always work well in practice, due to unintentional input [22,38].

Issues were raised about the limited battery life of smart glasses $[22,29,36,46]$. When recording video or using teleconferencing, the battery lasted 30-40 minutes and otherwise up to 10 hours [22]. Smart glasses were also found to produce a noticeable amount of heat $[28,36,46]$. When used clinically, smart glasses can be equipped with splatter eye protection [22] and were disinfected using disinfecting wipes [37] or by wiping with $70 \%$ isopropanol [22].

\section{Discussion}

\section{Overview}

This scoping review shows that smart glasses have both benefits and limitations in complex care environments. Increased understanding is provided about different situations where smart glasses might be used by health care professionals in clinical practice in anesthesia departments and ICUs. Research about 
smart glasses in clinical complex care environments is limited; several of the included studies were conducted in simulated settings or were minor clinical studies. The results also show that smart glasses could affect health care professionals and their performance, both positively (eg, through increased focus on procedural fields) and negatively (eg, causing discomfort during use). The quality of use of smart glasses is highlighted and there are some concerns that need attention before implementing the use of smart glasses in clinical complex care. This is all useful knowledge in the process of implementing smart glasses in anesthesia departments and ICUs.

\section{Principal Results and Comparison With Prior Work}

In complex care environments, technology is a prerequisite for the advanced care conducted. When health care professionals feel confident with equipment, complex care can be carried out in a safe way [47]. This review shows that patient management deteriorated if health care professionals became disturbed by the smart glasses. The results further highlight that there was a learning curve associated with the use of smart glasses. This indicates that user training is crucial when introducing smart glasses into complex care environments in order to maintain high-quality care and patient safety. The same is true for prudent implementation of any new technology. Both of these aspects have been discussed in relation to ICUs [21] and anesthesia departments seem to adhere to this as well. Generally, when implementing new technology, health care professionals need to see a clear benefit with the new device [48], and implementation in complex care environments does not seem to be an exception. To ensure patient privacy and patient safety, this review shows that ethical issues also need to be taken into consideration before implementing the use of smart glasses into complex care environments, as well as in other contexts $[13,15,17,49]$. Information security and privacy are well-known issues when implementing eHealth solutions in health care [50], and cybersecurity is at the top of ECRI's annual list of patient safety risks for 2019 [6]. Research regarding cybersecurity in health care has increased over the last 20 years, but there are still gaps to fill [51]. An extensive review about ethical issues related to smart glasses states that data security and privacy were the most frequently highlighted features found in the research [52]. Smart glasses as a new platform also imposes new ethical challenges related to privacy (eg, it is impossible for patients and health care professionals to know if or when they are being recorded or photographed by smart glasses). This makes context-specific development, implementation, and user routines important from an ethical view in order to provide patient safety [52]. Both intended and unintended consequences of new technology, such as smart glasses, need to be taken into account in the process of implementation [10], for example, in complex care environments.

The results show that smart glasses are versatile tools that could be used for several situations occurring in complex care environments. Patient vital signs are one important part of surveillance in complex care environments that are used to detect early changes in patients' conditions that might need urgent and immediate attention. This review shows that smart glasses presenting vital signs made health care professionals detect abnormal vital signs faster. The results also reveal that health care professionals did not have to turn their heads away from the patients in order to view monitors. This has been shown earlier in complex care environments with other types of more cumbersome head-mounted displays [53-55] and with smart glasses in surgical settings [17]. Not having to turn one's head away from the procedural field has been suggested to increase patient safety [53]. Further, the results show that smart glasses provided the possibility for uninterrupted monitoring when health care professionals needed to leave the traditional monitor out of sight. This is in line with earlier research conducted in surgical settings [49] and has been seen as a valuable asset for increased patient safety [21].

This review indicates that infrastructure, smart glasses' performance, and health care professionals will affect the usability of smart glasses in complex care environments. Infrastructure, such as $\mathrm{Wi}-\mathrm{Fi}$ and streaming, is a prerequisite for clinical use of most new technology [50], including smart glasses, and has been found to be a limitation in both surgical and nonsurgical settings $[15,18]$. This review found that complex care environments are no exception. Other technical limitations, including battery life and heat generation, were found in this review and are well known $[13,15,17,49]$. Technical improvements have been made recently [56], but no research was found using new, improved smart glasses. This review shows that the quality of photos and video captured by smart glasses seems to be sufficient for most clinical uses in complex care environments, but not for interpreting medical images with subtle findings. This has been concluded in the past for surgical settings [19], although other reviews have found photo and video quality to be a clinical limitation in various settings $[13,15]$. In complex care environments, monitoring vital signs in real time is one area of use for smart glasses, and this review found no negative results regarding image quality or the ability to detect abnormalities when smart glasses were used for viewing this kind of information.

This review shows that research about smart glasses in clinical complex care environments is limited. The results from this review can provide valuable knowledge to meet the growing interest from health care professionals, product developers, and researchers concerning smart glasses and their possible implementation in complex care environments.

\section{Methodological Considerations and Limitations}

Since a scoping review aims to conduct a wide rather than in-depth synthesis of research [25], PubMed and Scopus were chosen to search for articles from both health care and engineering. Perhaps more articles would have been found if more databases had been used, but PubMed and Scopus are big databases with wide coverage and were found sufficient. The search and screening processes were performed by the first author (CR) with support from experienced librarians. It is possible that relevant articles were missed and that these would have been found if this process had been performed by more than one researcher [27]. After reading the obtained full-text articles, inclusions and exclusions were discussed among the authors until consensus was reached. In the initial searches, "Google Glass" was found as a keyword, hence we chose to add this phrase as a search term. If we had added other brand 
names, we might have found additional articles, but Google Glass is the most well-known brand of smart glasses. Articles focusing on surgeons' use of smart glasses were not actively searched for; however, those found using our search terms were included if the inclusion criteria were met. The surgeons' focus was assumed to be mainly on the surgical field, but they often work closely with an anesthesiologist or a nurse anesthetist. It is possible that issues such as team communication or other applicable information were addressed in articles with a surgical focus, which could have added to our study as well. Reviews can be accepted in a scoping review, but we chose to exclude them since there is a risk of bias when interpreting other researchers' interpretations. Gray literature, such as dissertations and books, can also be included in a scoping review [25]. We found some gray literature during our searches (eg, correspondence and nonscientific articles) and they were included if inclusion criteria were met. Furthermore, a scoping review does not seek to assess the quality or impact of the results from the articles included [24,25]. This is why no quality assessment was made during the inclusion process. Articles with both qualitative and quantitative designs were included in our study, and text from results and tables were included in the analysis. The analysis process was discussed among the authors to increase credibility. The sixth optional stage in the scoping process (ie, step 6), where practitioners and consumers were included [25], added value to the study through creative discussions and input. After conducting this study, the authors conclude that a scoping review was suitable to fulfill the research objective.

\section{Conclusions}

Smart glasses were found to be both a helpful tool and a hindrance in caring situations that might occur in complex care environments. Thoughtful implementation and improved hardware are needed to meet health care professionals' needs. It has been stated earlier that all new technology brings new errors, and that new technologies should be tested before widespread implementation [7]. New technology might also bring ethical challenges [52]. Therefore, we conclude that more research is required to elucidate how smart glasses affect patient safety, health care professionals, and quality of care in complex care environments.

\section{Acknowledgments}

We would like to thank the librarians at Blekinge Institute of Technology for their valuable knowledge regarding database searches. We would also like to thank the PhD students and senior lecturers at Blekinge Institute of Technology for fruitful discussions and valuable input. This research was funded by the Scientific Council at Region Blekinge. The funder did not influence any part of the study.

\section{Conflicts of Interest}

None declared.

\section{Multimedia Appendix 1}

Final search terms.

[DOCX File, 14 KB-Multimedia Appendix 1]

\section{Multimedia Appendix 2}

Presentation of database searches.

[DOCX File, 39 KB-Multimedia Appendix 2]

\section{Multimedia Appendix 3}

Charting of articles included in the qualitative content analysis.

[DOCX File, 32 KB-Multimedia Appendix 3]

\section{References}

1. Aroch R, Berggren L, Edberg K, Kock Redfors M, Lifbom A, Malmberg A, et al. SFAI. Malmö, Sweden: Swedish Society for Anaesthesia and Intensive Care (SFAI); 2012 Nov 16. Treatment strategies for life support in intensive care URL: $\underline{\text { https:/ }}$ /sfai.se/wp-content/uploads/files/22-2\%20Treatment strategy.pdf [accessed 2020-03-04]

2. Nagelhout JJ, Elisha S. Nurse Anesthesia. 6th edition. St. Louis, MO: Elsevier; 2017.

3. Morton PG, Fontaine DK. Critical Care Nursing: A Holistic Approach. 11th edition. Philadelphia, PA: Wolters Kluwer; 2018.

4. Patient Safety: Making Health Care Safer. Geneva, Switzerland: World Health Organization; 2017. URL: https://tinyurl. com/uj7lyfy [accessed 2020-03-04]

5. Laila SA, Ahmed NTM, Mogahed MMA. Nurses' Perception Regarding the Use of Technological Equipment in the Critical Care Units. Journal of American Science 2011;7(10):545-552 [FREE Full text] [doi: 10.7537/marsjas071011.67]

6. 2019 Top 10 Health Technology Hazards: Executive Brief. A Report from Health Devices. Plymouth Meeting, PA: ECRI Institute; 2018. URL: https://www.ecri.org/Resources/Whitepapers and reports/Haz 19.pdf [accessed 2020-03-10] 
7. Hughes RG, editor. Patient Safety and Quality: An Evidence-Based Handbook for Nurses. Rockville, MD: Agency for Healthcare Research and Quality; 2008.

8. Pfrimmer DM, Johnson MR, Guthmiller ML, Lehman JL, Ernste VK, Rhudy LM. Surveillance: A Nursing Intervention for Improving Patient Safety in Critical Care Environment. Dimens Crit Care Nurs 2017;36(1):45-52. [doi: $10.1097 /$ dcc. 0000000000000217$]$

9. Nilsson U, Jaensson M. Anesthetic nursing: Keep in touch, watch over, and be one step ahead. J Perianesth Nurs 2016 Dec;31(6):550-551. [doi: 10.1016/j.jopan.2016.09.005] [Medline: 27931710]

10. Wüller H, Garthaus M, Remmers H. Augmented reality in nursing: Designing a framework for a technology assessment. Stud Health Technol Inform 2017;245:823-827. [Medline: 29295213]

11. Iqbal MH, Aydin A, Brunckhorst O, Dasgupta P, Ahmed K. A review of wearable technology in medicine. J R Soc Med 2016 Oct;109(10):372-380 [FREE Full text] [doi: 10.1177/0141076816663560] [Medline: 27729595]

12. Klein GO, Singh K, von Heideken J. Smart glasses: A new tool in medicine. Stud Health Technol Inform 2015;216:901. [Medline: 26262203]

13. Mitrasinovic S, Camacho E, Trivedi N, Logan J, Campbell C, Zilinyi R, et al. Clinical and surgical applications of smart glasses. Technol Health Care 2015;23(4):381-401. [doi: 10.3233/THC-150910] [Medline: 26409906]

14. Google Help. Tech specs URL: https://support.google.com/glass/answer/3064128?hl=en\&ref_topic=3063354 [accessed 2018-09-13]

15. Dougherty B, Badawy SM. Using Google Glass in nonsurgical medical settings: Systematic review. JMIR Mhealth Uhealth 2017 Oct 19;5(10):e159 [FREE Full text] [doi: 10.2196/mhealth.8671] [Medline: 29051136]

16. Wrzesinska N. MEDtube. 2015 Dec. The use of smart glasses in healthcare - review URL: https://medtube.net/science/ wp-content/uploads/2017/03/The-use-of-smart-glasses-in-healthcare-\%E2\%80\%93-review.pdf [accessed 2020-03-10]

17. Kolodzey L, Grantcharov PD, Rivas H, Schijven MP, Grantcharov TP. Wearable technology in the operating room: A systematic review. BMJ Innov 2016 Dec 21;3(1):55-63. [doi: 10.1136/bmjinnov-2016-000133]

18. Wei NJ, Dougherty B, Myers A, Badawy SM. Using Google Glass in surgical settings: Systematic review. JMIR Mhealth Uhealth 2018 Mar 06;6(3):e54 [FREE Full text] [doi: 10.2196/mhealth.9409] [Medline: 29510969]

19. Davis CR, Rosenfield LK. Looking at plastic surgery through Google Glass: part 1. Systematic review of Google Glass evidence and the first plastic surgical procedures. Plast Reconstr Surg 2015;135(3):918-928. [doi: 10.1097/prs.0000000000001056]

20. Block FE, Yablok DO, McDonald JS. Clinical evaluation of the 'head-up' display of anesthesia data. Preliminary communication. Int J Clin Monit Comput 1995 Feb;12(1):21-24. [doi: 10.1007/bf01142442] [Medline: 7782663]

21. Romare C, Hass U, Skär L. Healthcare professionals' views of smart glasses in intensive care: A qualitative study. Intensive Crit Care Nurs 2018 Apr;45:66-71 [FREE Full text] [doi: 10.1016/j.iccn.2017.11.006] [Medline: 29291922]

22. Muensterer OJ, Lacher M, Zoeller C, Bronstein M, Kübler J. Google Glass in pediatric surgery: An exploratory study. Int J Surg 2014;12(4):281-289 [FREE Full text] [doi: 10.1016/j.ijsu.2014.02.003] [Medline: 24534776]

23. Drake-Brockman TF, Datta A, von Ungern-Sternberg BS. Patient monitoring with Google Glass: A pilot study of a novel monitoring technology. Paediatr Anaesth 2016 May;26(5):539-546. [doi: 10.1111/pan.12879] [Medline: 26992465]

24. Polit DF, Beck CT. Nursing Research: Generating and Assessing Evidence for Nursing Practice. 10th edition. Philadelphia, PA: Wolters Kluwer; 2016.

25. Arksey H, O'Malley L. Scoping studies: Towards a methodological framework. Int J Soc Res Methodol 2005 Feb;8(1):19-32. [doi: 10.1080/1364557032000119616]

26. Tricco AC, Lillie E, Zarin W, O'Brien KK, Colquhoun H, Levac D, et al. PRISMA extension for scoping reviews (PRISMA-ScR): Checklist and explanation. Ann Intern Med 2018 Oct 02;169(7):467-473. [doi: 10.7326/M18-0850] [Medline: 30178033]

27. Levac D, Colquhoun H, O'Brien KK. Scoping studies: Advancing the methodology. Implement Sci 2010 Sep 20;5:69 [FREE Full text] [doi: 10.1186/1748-5908-5-69] [Medline: 20854677]

28. Fernando S, Wenjin W, Kirenko I, de Haan G, Bambang-Oetomo S, Corporaal H, et al. Feasibility of contactless pulse rate monitoring of neonates using Google Glass. In: Proceedings of the 5th EAI International Conference on Wireless Mobile Communication and Healthcare (MOBIHEALTH'15). Brussels, Belgium: ICST (Institute for Computer Sciences, Social-Informatics and Telecommunications Engineering); 2015 Presented at: 5th EAI International Conference on Wireless Mobile Communication and Healthcare (MOBIHEALTH'15); October 14-16, 2015; London, UK p. 198-201 URL: https:/ /doi.org/10.4108/eai.14-10-2015.2261589 [doi: 10.4108/eai.14-10-2015.2261589]

29. Iqbal MH, Aydin A, Lowdon A, Ahmed HI, Muir GH, Khan MS, et al. The effectiveness of Google Glass as a vital signs monitor in surgery: A simulation study. Int J Surg 2016 Dec;36(Pt A):293-297 [FREE Full text] [doi: 10.1016/j.ijsu.2016.11.013] [Medline: 27833004]

30. Liebert CA, Zayed MA, Aalami O, Tran J, Lau JN. Novel use of Google Glass for procedural wireless vital sign monitoring. Surg Innov 2016 Aug;23(4):366-373. [doi: 10.1177/1553350616630142] [Medline: 26848138]

31. PRISMA. URL: http://www.prisma-statement.org [accessed 2019-10-12]

32. García-Cruz E, Bretonnet A, Alcaraz A. Testing smart glasses in urology: Clinical and surgical potential applications. Actas Urol Esp 2018 Apr;42(3):207-211. [doi: 10.1016/j.acuro.2017.06.007] [Medline: 29037757] 
33. Gupta S, Boehme J, Manser K, Dewar J, Miller A, Siddiqui G, et al. Does wearable medical technology with video recording capability add value to on-call surgical evaluations? Surg Innov 2016 Oct;23(5):498-504. [doi: 10.1177/1553350616656278] [Medline: 27335083]

34. Skolnik AB, Chai PR, Dameff C, Gerkin R, Monas J, Padilla-Jones A, et al. Teletoxicology: Patient assessment using wearable audiovisual streaming technology. J Med Toxicol 2016 Dec;12(4):358-364 [FREE Full text] [doi: 10.1007/s13181-016-0567-3] [Medline: 27381429]

35. Drummond D, Arnaud C, Guedj R, Duguet A, de Suremain N, Petit A. Google Glass for residents dealing with pediatric cardiopulmonary arrest: A randomized, controlled, simulation-based study. Pediatr Crit Care Med 2017 Feb;18(2):120-127. [doi: 10.1097/PCC.0000000000000977] [Medline: 28165347]

36. Kassutto SM, Kayser JB, Kerlin MP, Upton M, Lipschik G, Epstein AJ, et al. Google Glass video capture of cardiopulmonary resuscitation events: A pilot simulation study. J Grad Med Educ 2017 Dec;9(6):748-754 [FREE Full text] [doi: 10.4300/JGME-D-17-00155.1] [Medline: 29270266]

37. Albrecht U, von Jan U, Kuebler J, Zoeller C, Lacher M, Muensterer OJ, et al. Google Glass for documentation of medical findings: Evaluation in forensic medicine. J Med Internet Res 2014 Feb 12;16(2):e53 [FREE Full text] [doi: 10.2196/jmir.3225] [Medline: 24521935]

38. Aldaz G, Shluzas LA, Pickham D, Eris O, Sadler J, Joshi S, et al. Hands-free image capture, data tagging and transfer using Google Glass: A pilot study for improved wound care management. PLoS One 2015;10(4):e0121179 [FREE Full text] [doi: 10.1371/journal.pone.0121179] [Medline: 25902061]

39. Spencer RJ, Chang PH, Guimaraes AR, Firth PG. The use of Google Glass for airway assessment and management. Paediatr Anaesth 2014 Sep;24(9):1009-1011. [doi: 10.1111/pan.12496] [Medline: 25039494]

40. Wüller H, Behrens J, Klinker K, Wiesche M, Krcmar H, Remmers H. Smart glasses in nursing - Situation change and further usages exemplified on a wound care application. In: Studies in Health Technology and Informatics Series. Volume 253: German Medical Data Sciences: A Learning Healthcare System. Amsterdam, the Netherlands: IOS Press; 2018:191-195.

41. Jeroudi OM, Christakopoulos G, Christopoulos G, Kotsia A, Kypreos MA, Rangan BV, et al. Accuracy of remote electrocardiogram interpretation with the use of Google Glass technology. Am J Cardiol 2015 Feb 01;115(3):374-377. [doi: 10.1016/j.amjcard.2014.11.008] [Medline: 25482681]

42. Schaer R, Salamin F, Jiménez del Toro OA, Atzori M, Müller H, Widmer A. Live ECG readings using Google Glass in emergency situations. In: Proceedings of the 37th Annual International Conference of the IEEE Engineering in Medicine and Biology Society (EMBC). 2015 Presented at: 37th Annual International Conference of the IEEE Engineering in Medicine and Biology Society (EMBC); August 25-29, 2015; Milan, Italy p. 315-318. [doi: 10.1109/EMBC.2015.7318363]

43. Spaedy E, Christakopoulos GE, Tarar MN, Christopoulos G, Rangan BV, Roesle M, et al. Accuracy of remote chest X-ray interpretation using Google Glass technology. Int J Cardiol 2016 Sep 15;219:38-40. [doi: 10.1016/j.ijcard.2016.05.070] [Medline: 27262231]

44. Stetler J, Resendes E, Martinez-Parachini JR, Patel K, Amsavelu S, Tarar MN, et al. Hands-free zoom and pan technology improves the accuracy of remote electrocardiogram interpretation using Google Glass. Int J Cardiol 2016 Feb 01;204:147-148. [doi: 10.1016/j.ijcard.2015.11.144] [Medline: 26657610]

45. Udani AD, Harrison TK, Howard SK, Kim TE, Brock-Utne JG, Gaba DM, et al. Preliminary study of ergonomic behavior during simulated ultrasound-guided regional anesthesia using a head-mounted display. J Ultrasound Med 2012 Aug;31(8):1277-1280. [doi: 10.7863/jum.2012.31.8.1277] [Medline: 22837293]

46. Wu TS, Dameff CJ, Tully JL. Ultrasound-guided central venous access using Google Glass. J Emerg Med 2014 Dec;47(6):668-675. [doi: 10.1016/j.jemermed.2014.07.045] [Medline: 25281180]

47. Tunlind A, Granström J, Engström A. Nursing care in a high-technological environment: Experiences of critical care nurses. Intensive Crit Care Nurs 2015 Apr;31(2):116-123. [doi: 10.1016/j.iccn.2014.07.005] [Medline: 25442241]

48. Gagnon MP, Desmartis M, Labrecque M, Car J, Pagliari C, Pluye P, et al. Systematic review of factors influencing the adoption of information and communication technologies by healthcare professionals. J Med Syst 2012 Feb;36(1):241-277 [FREE Full text] [doi: 10.1007/s10916-010-9473-4] [Medline: 20703721]

49. Vorraber W, Voessner S, Stark G, Neubacher D, DeMello S, Bair A. Medical applications of near-eye display devices: An exploratory study. Int J Surg 2014 Dec;12(12):1266-1272 [FREE Full text] [doi: 10.1016/j.ijsu.2014.09.014] [Medline: 25462704]

50. Ahmed B, Dannhauser T, Philip N. A systematic review of reviews to identify key research opportunities within the field of eHealth implementation. J Telemed Telecare 2019 Jun;25(5):276-285. [doi: 10.1177/1357633X18768601] [Medline: 29703127]

51. Jalali MS, Razak S, Gordon W, Perakslis E, Madnick S. Health care and cybersecurity: Bibliometric analysis of the literature. J Med Internet Res 2019 Feb 15;21(2):e12644 [FREE Full text] [doi: 10.2196/12644] [Medline: 30767908]

52. Hofmann B, Haustein D, Landeweerd L. Smart glasses: Exposing and elucidating the ethical issues. Sci Eng Ethics 2017 Jun;23(3):701-721. [doi: 10.1007/s11948-016-9792-z] [Medline: 27432401]

53. Ormerod DF, Ross B, Naluai-Cecchini A. Use of a see-through head-worn display of patient monitoring data to enhance anesthesiologists' response to abnormal clinical events. In: Proceedings of the 6th International Symposium on Wearable 
Computers (ISWC 2002). New York, NY: IEEE; 2002 Presented at: 6th International Symposium on Wearable Computers (ISWC 2002); October 7-10, 2002; Seattle, WA p. 131-132. [doi: 10.1109/ISWC.2002.1167229]

54. Liu D, Jenkins SA, Sanderson PM, Fabian P, Russell WJ. Monitoring with head-mounted displays in general anesthesia. Anesth Analg 2010;110(4):1032-1038. [doi: 10.1213/ane.0b013e3181d3e647]

55. Liu D, Sanderson PM, Jenkins SA, Watson MO, Russell WJ. Patient monitoring in anesthesia with a head-mounted display: Simulator studies and a clinical trial. In: Proceedings of the 53rd Annual Meeting of the Human Factors and Ergonomics Society. 2009 Presented at: 53rd Annual Meeting of the Human Factors and Ergonomics Society; October 19-23, 2009; San Antonio, TX p. 733-737. [doi: 10.1177/154193120905301121]

56. Stein S. CNET. 2017 Jul 18. Google Glass returns: This time, it's professional URL: https://www.cnet.com/news/ google-glass-2-goes-for-enterprise/ [accessed 2019-03-27]

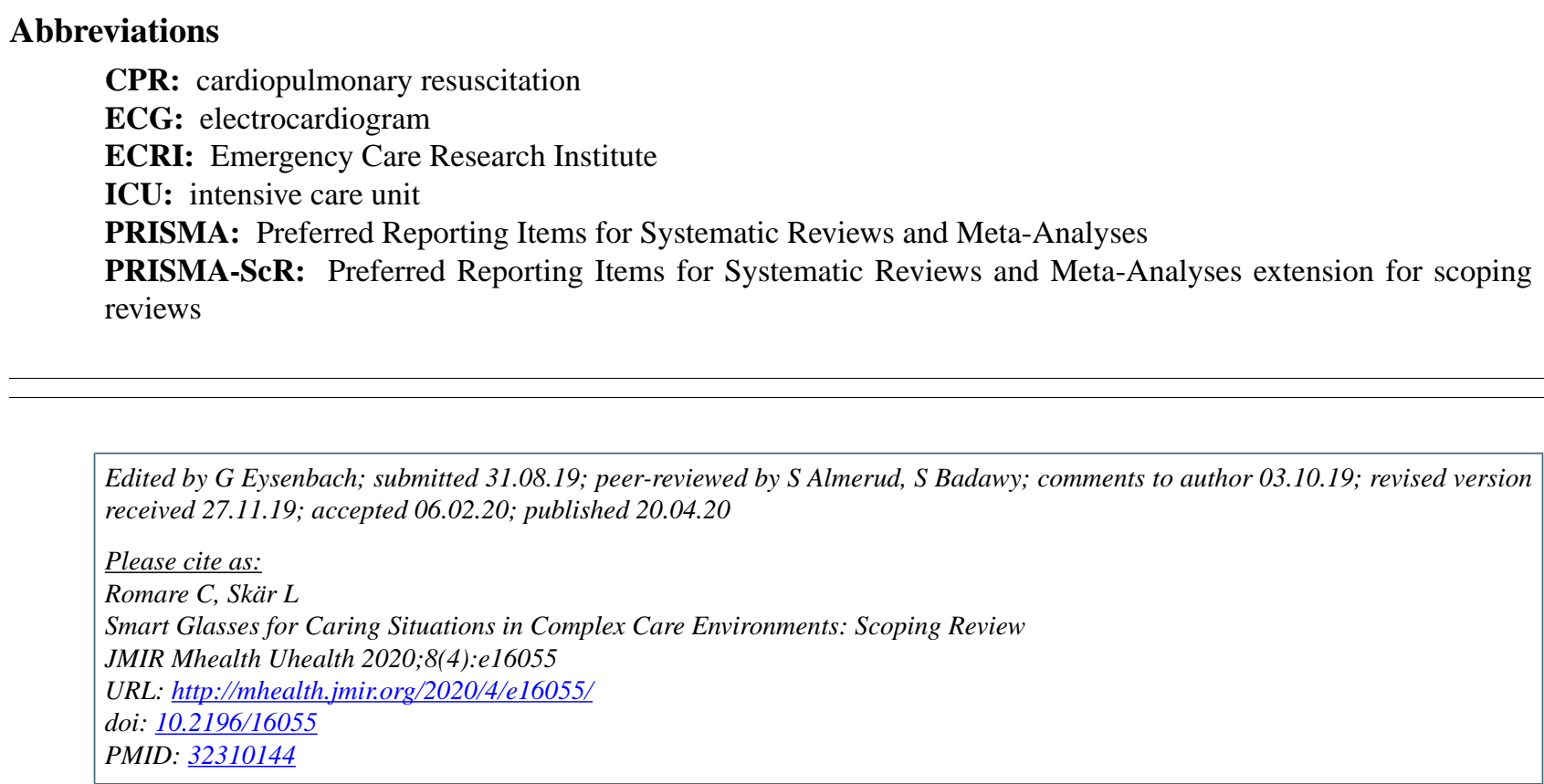

(C) Charlotte Romare, Lisa Skär. Originally published in JMIR mHealth and uHealth (http://mhealth.jmir.org), 20.04.2020. This is an open-access article distributed under the terms of the Creative Commons Attribution License (https://creativecommons.org/licenses/by/4.0/), which permits unrestricted use, distribution, and reproduction in any medium, provided the original work, first published in JMIR mHealth and uHealth, is properly cited. The complete bibliographic information, a link to the original publication on http://mhealth.jmir.org/, as well as this copyright and license information must be included. 